\title{
Optimal Policy with Heterogeneous Preferences
}

\section{Citation}

Louis Kaplow, Optimal Policy with Heterogeneous Preferences, 8 B. E. J. Econ. Analysis \& Pol'y 40 (2008).

\section{Published Version}

doi:10.2202/1935-1682.1947

\section{Permanent link}

http://nrs.harvard.edu/urn-3:HUL.InstRepos:12330894

\section{Terms of Use}

This article was downloaded from Harvard University's DASH repository, and is made available under the terms and conditions applicable to Other Posted Material, as set forth at http:// nrs.harvard.edu/urn-3:HUL.InstRepos:dash.current.terms-of-use\#LAA

\section{Share Your Story}

The Harvard community has made this article openly available.

Please share how this access benefits you. Submit a story.

Accessibility 


\title{
The B.E. Journal of Economic Analysis \& Policy
}

\section{Advances}

\section{Optimal Policy with Heterogeneous Preferences}

\author{
Louis Kaplow*
}

*Harvard University, meskridge@law.harvard.edu

\section{Recommended Citation}

Louis Kaplow (2008) "Optimal Policy with Heterogeneous Preferences," The B.E. Journal of Economic Analysis \& Policy: Vol. 8: Iss. 1 (Advances), Article 40.

Available at: http://www.bepress.com/bejeap/vol8/iss1/art40

Copyright (c)2008 The Berkeley Electronic Press. All rights reserved. 


\title{
Optimal Policy with Heterogeneous Preferences*
}

\author{
Louis Kaplow
}

\begin{abstract}
Optimal policy rules-including those regarding income taxation, commodity taxation, public goods, and externalities - are typically derived in models with homogeneous preferences. This article reconsiders many central results for the case in which preferences for commodities, public goods, and externalities are heterogeneous. When preference differences are observable, standard second-best results in basic settings are unaffected, except those for the optimal income tax. Optimal levels of income taxation may be higher, the same, or lower on types who derive more utility from various goods, depending on the nature of preference differences and the concavity of the social welfare function. When preference differences are unobservable, all policy rules may change. The determinants of even the direction of optimal rule adjustments are many and subtle.
\end{abstract}

KEYWORDS: heterogeneous preferences, optimal income taxation, commodity taxation, externalities, public goods, social welfare

*Harvard University and National Bureau of Economic Research. I am grateful to the editor, Don Fullerton, the referees, and workshop participants at Harvard and the NBER-especially Iván Werning - for comments, and to the John M. Olin Center for Law, Economics, and Business at Harvard University for financial support. 
Kaplow: Optimal Policy with Heterogeneous Preferences

\section{INTRODUCTION}

Most analytical work in public economics that derives rules for optimal policy assumes that preferences are homogeneous. This characterization applies, for example, to most of the literature on optimal income taxation, commodity taxation, public goods provision, and the control of externalities. The reason for this simplification is tractability; indeed, the second-best problems are complex even when preferences are stipulated to be homogeneous.

It is natural to explore whether and how standard results are modified when preferences are heterogeneous. Individuals may have ordinary differences in tastes: Some may prefer chocolate, others vanilla; some may love nature and thus highly value improvements to national parks or pollution regulations that restore wilderness habitats, whereas others may desire city life and accordingly prefer enhancements to urban amenities. Differences may also arise on account of physical and mental disabilities.

These possibilities raise a number of questions. Does Atkinson and Stiglitz's (1976) result on uniform commodity taxation survive the introduction of heterogeneity, and, if not, how do the results change? Is the Samuelson rule for public goods altered, or the Pigouvian dictum that corrective taxes and subsidies should equal the marginal harms and benefits (respectively) from externalities? Likewise, how are standard first-order conditions for optimal income taxation affected? How do the answers to such questions depend on whether differences in preferences are observable? Finally, how do they depend on the manner in which preferences differ? In other words, in what respects is the problem of preference heterogeneity itself a heterogeneous phenomenon?

A related, more focused set of questions may be directed at a particular set of results in public economics. Certain policy rules have been demonstrated to be optimal because following them generates Pareto improvements, one consequence of which is that the optimal rules are independent of the particular choice of social welfare function (SWF). This approach is featured in generalizations of Atkinson and Stiglitz (1976) on commodity taxation, as well as in work on public goods and on externalities. ${ }^{1}$ Yet when preferences are heterogeneous, Pareto improvements are highly unlikely. Virtually any policy reform, no matter how desirable, is likely to generate some losers because certain individuals have idiosyncratic preferences that are better served by the inefficient status quo. For example, even substantial reductions of a highly damaging pollutant at minimal cost may disfavor some whose bodies are insensitive to the pollutant and who especially enjoy polluting activities

(2005)

${ }^{1}$ See, for example, Kaplow (1996, 2006a, 2006b, 2006c, 2008), Konishi (1995), and Laroque

Published by The Berkeley Electronic Press, 2008 
that need to be curtailed. $\mathrm{Ng}(1984 \mathrm{~b})$ has suggested that, as a consequence of heterogeneity, we might instead ask whether policies offer a "quasi-Pareto" improvement, by which he means a gain, on average, to individuals at every level of income (thereby addressing standard distributive concerns). Nevertheless, it is appropriate to explore formally and systematically how, if at all, the derivations and results in this literature need to be adjusted in light of preference heterogeneity.

This article undertakes a preliminary exploration of these questions. Section 2 presents a model with a nonlinear income tax and commodity taxes where individuals' preferences for commodities are heterogeneous. In section 3, the model is analyzed for the case in which preference differences are observable. This case is of interest because it is more tractable and transparent, facilitates examination of the case with unobservable heterogeneity, and has some elements of realism (for example, certain physical disabilities, with associated differences in preferences, are observable). It is straightforward to show that the Atkinson-Stiglitz result concerning the optimality of uniform commodity taxation and a variety of extensions are preserved. The reason is that, with observability, the nonlinear income tax can be preference-type-specific, which makes it possible to conduct the analysis of commodity taxation as if preferences were identical.

Accordingly, the bulk of the analysis in section 3 focuses on optimal income taxation results, which do differ. Optimal levels of income taxation may be higher, the same, or lower for individuals with preferences that yield higher utility for a given level of disposable income. The character of the result depends on the nature of preference differences and on the concavity of utility functions and of the SWF. An implication is that some results in prior literature attributed to preference heterogeneity are in fact a product of the choice to model heterogeneity in one particular way; other choices would have yielded different, even opposite, conclusions.

Section 4 considers the case in which preference differences are unobservable. It is demonstrated that uniform commodity taxation is no longer desirable. However, determinants of the direction and magnitude of deviations are complex and subtle. Differentials in commodity taxation tend to be optimal to the extent that their effects are similar to those of the adjustments to the income tax that would have been optimal if preference differences were observable.

Section 5 extends the results to policy rules for public goods and externalities, for which many of the conclusions are analogous to those for commodity taxation: When preference differences are observable, one continues to obtain benchmark results of first-best policy rules, notably, the Samuelson rule for public goods and the Pigouvian prescription for complete internalization of externalities. When preference differences are not observable, deviations depend on some of the same sorts of factors as with commodity taxation and serve the same 
purpose of indirectly substituting for the redistributive adjustments to the income tax that would have been optimal in the case of observability.

Section 6 briefly considers pertinent issues in welfare economics, namely, concerning the concavity of the SWF and interpersonal comparisons of utility. The motivation is that many of the results concerning heterogeneity — including the signs of the optimal adjustments as well as the magnitudes-depend on these aspects of welfare aggregation. Moreover, when preferences and thus commodity demands are heterogeneous, it is no longer possible to address interpersonal comparisons by simply treating everyone as if they had the same utility function. Concluding remarks are offered in section 7 .

Prior work on heterogeneity is of a number of types. Saez (2002) introduces heterogeneity regarding previously established deviations from the Atkinson-Stiglitz uniform commodity tax result: Atkinson and Stiglitz (1976) had shown that relaxing labor separability favors nonuniformity, and Mirrlees (1976) had shown that relaxing the assumption that preferences are independent of earning ability favors nonuniformity. Saez (2002) demonstrates that, when these relationships are not deterministic but rather reflect mere correlations, similar results obtain. ${ }^{2}$ By contrast, the present article abstracts from these two considerations and examines instead effects of heterogeneity that pertain more directly to the marginal social value of redistribution than to the labor-leisure distortion caused by income taxation.

Some discussion of these other sorts of heterogeneity appears in prior literature - especially on public goods, e.g., Hylland and Zeckhauser (1979), Ng (1984b), Boadway and Keen (1993), and Kaplow (1996) — but does not suggest or demonstrate the results derived here. Other papers have examined certain technical aspects of the nonlinear income tax problem when additional dimensions are introduced. See Ebert (1988) and Tarkiainen and Tuomala (1999), and also Armstrong and Rochet (1999) on multidimensional screening more generally. Tarkiainen and Tuomala (1999) also present some simulations, but their example has special features. In addition, it is hard to interpret their simulation results regarding differences in optimal redistribution in the presence of heterogeneity because the means of the parameters in their two-dimensional case differ, often significantly, from the values in their one-dimensional case. Boadway et al. (2002) focus on which self-selection constraints are binding in a model in which preferences are of two types, and Cremer et al. (2001) discuss modifications to the Atkinson and Stiglitz (1976) result when individuals differ in unobservable endowments.

Finally, some additional papers introduce specific forms of heterogeneity in certain variations of the income or commodity tax problem. Blackorby and

\footnotetext{
${ }^{2}$ Saez (2002) notes the existence of other forms of preference heterogeneity but does not analyze the relationship between different specifications of preferences and the resulting social welfare weights, which is the focus here.
} 
Donaldson (1988) find that in-kind provision of medical care-or, if that is not feasible, differential taxation of medical care and other goods - may be optimal when unobservable differences in medical needs exist. Sandmo (1993) explores some optimal income tax implications of heterogeneous tastes for work in a model with no differences in earning abilities and only one type of consumption. Marchand, Pestieau, and Racionero (2003) consider differences in the source of disutility to labor that are unobservable, are relevant to social welfare under their chosen nonwelfarist SWF, and are related differently to demands for particular commodities. Hellwig (2004) addresses optimal pricing by a public monopolist with heterogenous consumers. And Fleurbaey (2006) introduces preference heterogeneity along with a nonwelfarist SWF that features a laissez-faire criterion that favors noninterference with consumption choices.

As a whole, prior work does not address most of the questions examined here or how the answers depend on observability or on the policy context-commodity taxation, public goods, externalities, or pure income taxation. Of particular note, past inquiries, including those by this author, typically speak of heterogeneity as if it were a unitary phenomenon when making general conjectures about how results may change with heterogeneity or when examining particular models. By contrast, the present analysis allows preferences among commodities (or public goods or external effects) to differ in various ways and finds that whether results change and, when they do, in what direction depend on the nature of the heterogeneity that is introduced.

\section{FRAMEWORK}

\subsection{MODEL}

The model has $n$ commodities, indexed by $i$; a particular commodity is denoted $x_{i}$. Individuals choose labor effort, $l$, and commodity vectors, $x$, to maximize utility $u(x, l, \theta)$, where $\theta$ is a vector of preference parameters. The consumer price vector is $q$, taken to be the sum of fixed producer prices $p$ and a commodity tax vector $\tau$. Commodity taxes may be negative, i.e., subsidies. The nonlinear income tax, $T(w l)$, is a function of individuals' income, $w l$, the product of their unobservable wage rate $w$ and labor effort. The budget constraint is

$$
\text { (2.1) } q x=w l-T(w l) \text {. }
$$

The government chooses the commodity tax vector $\tau$-equivalently, the consumer price vector $q$-and the nonlinear income tax $T$ to maximize social welfare, given by 
(2.2) $S W=\int W(v(w, \theta, \tau, T)) d F(w, \theta)$,

where $W$ is a weakly concave function, $v$ is an individual's indirect utility function-indicating the maximized value of $u$ for ability level $w$ and preference parameters $\theta$ when the tax regime $(\tau, T)$ is taken as given - and $F$ is the cumulative distribution function. The government also faces a revenue constraint under which commodity tax plus income tax revenue must meet a fixed target $R$, but this requirement does not need to be examined explicitly here.

Much of the analysis focuses on the case in which the preference parameters $\theta$ are observable. Accordingly, the pertinent nonlinear income tax schedules are $T(w l, \theta)$; that is, each preference type $\theta$ faces a separate income tax schedule. It is assumed that commodity taxes, $\tau$, cannot be type-specific because of the possibility of resale. This restriction often does not matter (comments in footnote 5 discuss the implications when it does).

Taking commodity taxes as given, the optimal nonlinear income tax is characterized by a first-order condition derived, for example, in Atkinson and Stiglitz (1980), who make various simplifications, notably, that utility is separable between consumption and labor effort, and offer other caveats that are not examined further here. Their condition can be expressed as:

$$
\text { (2.3) } \frac{T^{\prime}(w l, \theta)}{1-T^{\prime}(w l, \theta)}=\frac{\int_{w}^{\infty} \frac{v_{c}(w, \theta)}{v_{c}(\omega, \theta)}\left(1-\frac{W^{\prime}(v(\omega, \theta)) v_{c}(\omega, \theta)}{\lambda}\right) f(\omega, \theta) d \omega}{\varepsilon w f(w, \theta)} \text {. }
$$

Primes denote derivatives with respect to income, that is, $w l ; v_{c}$ is the marginal utility of consumption; $\omega$ is the variable of integration, indexing types with ability above $w ; f$ is the density function derived from $F$; $\lambda$ is the marginal social value of a dollar (i.e., the shadow price on the government's revenue constraint); and $\varepsilon$ (implicitly a function of $w$ and $\theta$ ) is related to the labor supply elasticity. Note that expression (2.3) suppresses the fact that indirect utility, $v$, depends on $\tau$, which is taken as given, and on $T$.

The left side of expression (2.3) indicates the marginal income tax rate as a fraction of the untaxed proportion of marginal earnings. On the right side, the denominator indicates the marginal distortionary cost of a higher marginal income tax rate. It is the product of three components: $\varepsilon$ (as noted, a term related to the labor supply elasticity); $w$, which measures the productivity lost by each unit reduction in labor supply (and likewise indicates the marginal revenue loss); and $f(w, \theta)$, which is the portion of the population that is distorted at the margin. 
The integral in the numerator is related to the benefit from higher marginal income tax rates in terms of revenue raised on those earning more than $w l$, for whom a marginal income tax rate increase at income $w l$ is inframarginal. This integral is from the marginal type, $w$, who faces the marginal rate increase, to the upper limit of the distribution of ability types, taken here to be unbounded. The key term for present purposes is that in the large parentheses in the integrand. The numerator of the latter component, $W^{\prime} v_{c}$, is the marginal contribution to social welfare caused by a unit increase in utility of the pertinent type multiplied by that type's marginal utility of consumption - i.e., net-of-income-tax income or disposable income. This term is divided by $\lambda$, which converts units of social welfare into dollars. Accordingly, as the overall marginal contribution of individuals' consumption to social welfare is greater (ceteris paribus), the term in parentheses is smaller, the value of the integral is lower, and thus the optimal marginal tax rate is lower.

A significant caveat to this analysis is that this first-order condition (2.3) characterizes optimal marginal tax rates but does not tell us the intercept of the schedule, $T(0)$, which typically is negative (a uniform grant). Suppose, for example, that all individuals in some group, $\theta$, have a higher welfare weight. This weight tends to favor a lower intercept (a larger transfer), which tends to offset the justmentioned effect on optimal marginal tax rates. Accordingly, the discussion that follows usually refers, for example, to a factor favoring a lower level of income taxation on a group, not disentangling the extent to which this result is optimally effectuated through a lower intercept and lower marginal tax rates.

It is also important to keep in mind that, for the case in which $\theta$ is observable, the first-order condition is separately stated for each $\theta$. These separate conditions are linked to the single social optimization problem by the common shadow price $\lambda$. When comparing groups with different values of $\theta$, those with higher marginal social valuations of consumption should, ceteris paribus, be subject to lower levels of income taxation. This "ceteris paribus" statement is, however, highly problematic because $\theta$ affects other components in expression (2.3) as well. (Notably, a given ability type $w$ with a different $\theta$ may choose to supply a different level of labor effort, $l$, and thus earn a different level of income, $w l$.) Nevertheless, the standard practice of interpreting this sort of first-order condition term by term provides some valuable insight into this highly complicated problem.

The analysis here focuses on utility functions that are at least weakly separable in labor. Specifically, attention is confined to forms of $u(x, l, \theta)$ that can be written as $u\left(u^{1}(x, \theta), l, \theta\right)$. This restriction is meaningful because $x$ is a vector. The weak separability assumption means that, in allocating resources among the $x_{i}$ 's, it is immaterial how much labor effort, $l$, was required to produce the individual's level of disposable income. Likewise, the allocation among the $x_{i}$ 's does not directly influence the choice of labor effort, $l$; all that matters is the level of subutility, $u^{1}(x, \theta)$, that is obtained. 


\subsection{Types of Preference Heterogeneity}

As suggested in the introduction, individuals' preferences can vary in a number of qualitatively different ways. Before stating possibilities in terms of the functional form of the utility function and analyzing them formally, it is useful to articulate intuitively the sorts of heterogeneity that are examined. Because heterogeneity may well be good-specific, the discussion throughout is in terms of specific commodities rather than utility as a whole. Although some of the depictions may be somewhat elusive due to the informality, each type of heterogeneity corresponds to specific preference parameters that are introduced momentarily and then analyzed, thereby eliminating any residual ambiguity.

First (corresponding to $\alpha$, just below), individuals may vary in their sensitivity to a good's contribution to utility. For example, two individuals may enjoy ice cream and find that its consumption is subject to diminishing returns in the same manner, but one may have a higher overall sensitivity; perhaps ice cream, consumed at any given level, delivers twice as much utility to this individual. The individual with greater sensitivity is shown to have a higher marginal utility of disposable income, ceteris paribus, as a result.

Second $(\beta)$, individuals may differ in their ability to convert raw commodities into utility. The difference may be physical (one is able to make use of the product with less waste), physiological, or psychological. For example, individuals with a greater body mass or rate of metabolism may convert calories to resulting states of being at different rates. Some readers may find this type of heterogeneity to be similar to the first, but, as will be seen, it is importantly different, specifically in terms of how this difference interacts with diminishing returns in consumption; see the discussion of parameter $\rho$ below. As is demonstrated, those who are more efficient converters of commodities into utility may have a higher or a lower marginal utility of income, ceteris paribus, depending on this curvature parameter.

Third $(\gamma)$, individuals may in essence start their consumption at different points along a utility curve. For example, one may need eyeglasses or corrective surgery to possess the same vision or other attribute that others come by naturally. Individuals who are relatively blessed in this regard are shown to have a lower marginal utility of income, ceteris paribus, because their situation is equivalent to being endowed with greater initial income.

Fourth ( $\delta$ ), some individuals' utilities may have different base points. Perhaps due to a different psychological constitution, some may achieve higher or lower well-being for any given level of consumption. Individuals better off in this respect have a higher utility level but the same marginal utility of income as others do, ceteris paribus. 
The present analysis distinguishes these types of heterogeneity because they have qualitatively different effects on behavior and on optimal policies due to their different effects on individuals' marginal utility of income. In order to understand these distinctions among types of heterogeneity more concretely and to derive their consequences, it is useful to explore a simple, specific utility function that embodies all four types in a transparent fashion. The functional form to be considered is a fiveparameter (by $n$ ) function. Thus, let $\theta=(\alpha, \beta, \gamma, \delta, \rho)$, where each of these parameters may take on a different value for each commodity. (The fifth parameter, $\rho$, is the curvature parameter noted in the discussion of $\beta$.) This utility function is ${ }^{3}$

(2.4) $u(x, l, \alpha, \beta, \gamma, \delta, \rho)=\sum_{i=1}^{n}\left(\alpha_{i} \frac{\left(\beta_{i} x_{i}+\gamma_{i}\right)^{1-\rho_{i}}}{1-\rho_{i}}+\delta_{i}\right)-z(l)$.

It is assumed that $\alpha_{i}>0, \beta_{i}>0, \rho_{i}>0$ (each for all $i$ ), $z^{\prime}>0$, and $z^{\prime \prime}>0$. (For the case in which the concavity parameter, $\rho_{i}$, equals 1 , the fractional expression is replaced by $\ln \left(\beta_{i} x_{i}+\gamma_{i}\right)$; it will be apparent below that using this alternative yields the same first-order conditions, so none of the analysis is affected.) It is helpful for most discussion to think of a base case in which, for any commodity $x_{i}, \alpha_{i}=\beta_{i}=1$ and $\gamma_{i}=\delta_{i}=0$. Relative to that case, a higher $\alpha_{i}$ magnifies the contribution of $x_{i}$ to utility without being subject to the curvature effect through $\rho_{i}$; a higher $\beta_{i}$ magnifies the contribution of $x_{i}$ to utility but is subject to the curvature effect through $\rho_{i}$; $\gamma_{i}$ adds to utility in a manner that is subject to the curvature effect through $\rho_{i}$; and $\delta_{i}$ adds to utility without being subject to the curvature effect through $\rho_{i}$. (The $\delta_{i}$ 's are interchangeable - only their summation matters - but this notation is employed to maintain symmetry.) It is obvious that raising any of these four parameters raises utility; however, as will be explored, they have a qualitatively different effect on marginal utility and thus may have a different effect on optimal policies.

${ }^{3}$ The functional form in expression (2.4) resembles and in respects generalizes a number of standard utility functions. In a constant elasticity of substitution (CES) utility function, $\beta=1, \gamma=0$, $\delta=0$, the $\alpha$ 's may sum to one and do not vary across individuals, $\rho$ varies neither across commodities nor individuals, and the entire summation is raised to the power $1 / 1-\rho$, which is an immaterial difference for present purposes. Cobb-Douglas utility is equivalent to the special case described in the text following expression (2.4) in which $\rho=1$. Finally, the parameter $\gamma$ is suggestive of a StoneGeary utility function, where it is typical to take each $\gamma_{i}$ to be negative (and to replace the summation with a product) so that the $\gamma_{i}$ represent subsistence levels of each commodity (in that, if such level is not exceeded, total utility is zero regardless of the level of consumption of other commodities). 
Kaplow: Optimal Policy with Heterogeneous Preferences

\section{ANALYSIS WITH OBSERVABLE TYPES}

\subsection{Optimal Commodity TAXation}

For the case in which individuals' preference parameters are observable, the existence of any of these types of preference heterogeneity has no significant impact on results concerning optimal commodity taxation in the presence of a nonlinear income tax. Specifically, weak separability of labor is sufficient to generate the result that no differentiation is optimal, which implies that optimal commodity taxes may be taken to be zero. This result does not require that the income tax be optimal, and it can be extended to show the optimality of various partial commodity tax reforms, such as moving differentiated commodity taxes proportionally toward uniformity.

Upon reflection, this conclusion should not be surprising. The reason that results in the homogeneous case carry over in the presence of heterogeneity when preference differences are observable is that, as is now elaborated, one can decompose the latter problem into a number of cases of the former. Furthermore, because the proof technique that is employed in certain papers in the relevant literature does not depend on the optimality of the income tax (which is affected by heterogeneity) or on any global properties of the system, the fact that these features may change in the presence of preference heterogeneity does not affect the results regarding optimal commodity taxation.

To see that this is indeed the case, begin by observing that the proof of all of the results on commodity taxation - including that no differentiation is optimal and that partial reforms moving proportionately toward neutrality are desirable - in Kaplow (2006a) and in some other work, e.g., Laroque (2005), requires only weak separability of labor and that the subutility function of commodities, $u^{1}$ in the above formulation, be common. Regarding the latter, when preference parameters are observable, the problem can be analyzed as if preferences are identical because the nonlinear income tax can be preference-type-specific.

Rather than reconstructing the pertinent proofs, it should be sufficient to review their two key steps. The first step - the one that depends on homogeneous preferences-involves constructing an adjustment to the preexisting nonlinear income tax so that, when combined with the commodity tax reform-say, a move toward uniformity-everyone's utility is held constant. Specifically, this intermediate tax schedule, $T^{\circ}(w l)$, is defined such that $V(\tau, T, w l)=V\left(\tau^{*}, T^{\circ}, w l\right)$ for all $w l$-where $V$ is an indirect subutility function indicating the maximized value of what is here denoted $u^{1}$. For this construction to be feasible-i.e., for the same tax schedule to preserve subutility for all individuals - it is necessary that the underlying 
subutility functions be identical (but homogeneity in other respects is not required). ${ }^{4}$ Here, $u^{1}$ depends on $\theta$. However, when $\theta$ is observable, a separate income tax schedule is applied for each $\theta$; hence, a separate income tax adjustment may be employed as well. Thus, for each $\theta$, one can define $T^{\circ}(w l, \theta)$ as the adjustment to $T(w l, \theta)$ such that $V(\tau, T, w l, \theta)=V\left(\tau^{*}, T^{\circ}, w l, \theta\right)$ for all $w l$.

At this point, the remainder of the proofs in Kaplow (2006a) and in other pertinent papers goes through. In particular, it was shown there that this tax adjustment, which holds utility constant for each level of labor supply, does in fact induce individuals to choose the same level of labor supply as they did initially. The reasoning is, in essence, that the tax adjustment, when combined with the contemplated commodity tax adjustment, produces the same mapping from $l$ to total utility as was produced initially, so whatever $l$ maximized utility initially continues to do so after the reform.

To complete the proofs, it was demonstrated that commodity tax reforms that are efficient in the narrow, conventional sense-including moves toward uniformity - produce a revenue surplus. The intuition is that, since the income tax adjustment holds utility constant, yet efficiency rises, the income tax adjustment must be absorbing a dollar amount that is equivalent to the underlying efficiency gain. The resulting surplus, in turn, can be rebated pro rata, generating a Pareto improvement. $^{5}$

\subsection{OPTIMAL INCOME TAXATION}

With observable differences in preferences, it is optimal to employ different nonlinear income tax schedules. In this case, commodity taxes can be put to the side; specifically, they are taken to be zero. The focus is on how the marginal social contribution of disposable income to social welfare, $W^{\prime} v_{c}$, depends on $\theta$ when

${ }^{4}$ For further discussion, consider Boadway and Keen's (1993) examination of preference heterogeneity in the public goods context (in an analysis that employs first-order conditions for social welfare maximization rather than constructing Pareto improvements).

${ }^{5}$ Note that the requirement that commodity taxes be anonymous (i.e., not type-specific) is not restrictive because all types should face the same (zero) tax vector. If one relaxed the labor separability assumption, however, the optimal commodity tax problem would be complicated by the fact that the optimal differentiation, which reflects the degree to which various commodities are complements to or substitutes for labor, could depend on individuals' specific preferences. (Suppose, for example, that $x_{i}$ was a complement and $x_{j}$ was a substitute for type $\theta_{1}$ but the opposite was true for type $\theta_{2}$.) Ideally, each type would be subject to distinctive commodity taxes and subsidies, but if this is infeasible the optimum would roughly reflect a weighted average of what would be optimal for different types considered separately. When the optimum for each type is the same, which is true with separability, this complication does not arise. 
preferences have the form given by expression (2.4). ${ }^{6}$ As already noted, it is obvious that utility levels rise with $\alpha, \beta, \gamma$, and $\delta$. To confirm this, note that the partial derivative of $u$ is clearly positive for each of these parameters, and the total derivative has the same value (the envelope theorem). If the SWF is utilitarian, which means that $W^{\prime}$ is constant, this feature is of no consequence. If instead the SWF is strictly concave, i.e., $W^{\prime \prime}<0$, then a group with a higher value of any of the parameters should, ceteris paribus, face higher levels of income taxation because the marginal contribution of their utility to social welfare is lower on account of their already being better off.

Next, consider how raising any of these four parameters affects the marginal utility of consumption, $v_{c}$, which is relevant to the marginal social welfare gain from additional disposable income regardless of the concavity of $W$ (short of maximin, wherein the welfare weight on everyone but the least-well-off individual is zero). The key concept here is that a parameter that is associated with a higher marginal utility of consumption calls for lower levels of taxation. As mentioned in subsection 2.1 , such lower taxation might be reflected in a more generous grant at zero income or in lower marginal tax rates.

Effects on marginal utility from the different types of heterogeneity are, as suggested in subsection 2.2, quite varied. To analyze them, begin with individuals' first-order conditions. When expression (2.4) is maximized subject to the budget constraint), we have, for each $x_{i}$,

$$
\text { (3.1) } \alpha_{i} \beta_{i}\left(\beta_{i} x_{i}+\gamma_{i}\right)^{-\rho_{i}}=\mu q_{i} \text {, }
$$

where $\mu$ is the marginal utility of disposable income (the shadow price on the budget constraint). This $\mu$ is also equal to $v_{c}$, employing the notation of the indirect utility function from expressions (2.2) and (2.3). It is useful to restate these conditions as

\footnotetext{
${ }^{6}$ The idea of analyzing policies' effects on different individuals by focusing on the marginal contribution to social welfare of a dollar distributed to different types of individuals is associated with Diamond (1975). Note further that the analysis articulated in the text is incomplete because of other aspects of the social first-order condition for optimal marginal income tax rates (2.3) that may differ, other standard caveats in interpreting first-order conditions to make conjectures about the optimum, and difficulties of comparing optimal income tax schedules across groups because individuals of a given earning ability $w$ may choose to exert different labor effort $l$ and thus earn different income $w l$ if their preferences differ.
} 
(3.2) $x_{i}=\frac{\left(\frac{\alpha_{i} \beta_{i}}{\mu q_{i}}\right)^{1 / \rho_{i}}-\gamma_{i}}{\beta_{i}}$.

Expression (3.2) indicates how each of the $x_{i}$ 's is a function of the preference parameters for the corresponding good, the good's consumer price, which is taken here to be constant, and the marginal utility of consumption, $\mu$. The first-order condition for labor effort is

$$
\text { (3.3) } z^{\prime}(l)=w\left(1-T^{\prime}(w l)\right) \mu \text {. }
$$

The task is to determine how $\mu$ changes with each of the preference parameters. It is convenient to let a generic preference parameter (aside from $\rho$ ) for good $k$ be denoted $\phi_{k}$. Differentiating the budget constraint (2.1) with respect to $\phi_{k}$ yields

(3.4) $q_{k} \frac{\partial x_{k}}{\partial \phi_{k}}+\sum_{i=1}^{n}\left(q_{i} \frac{\partial x_{i}}{\partial \mu} \frac{d \mu}{d \phi_{k}}\right)=w\left(1-T^{\prime}\right) \frac{d l}{d \mu} \frac{d \mu}{d \phi_{k}}$.

Rearranging terms allows us to state

(3.5) $\frac{d \mu}{d \phi_{k}}=\frac{q_{k} \frac{\partial x_{k}}{\partial \phi_{k}}}{w\left(1-T^{\prime}\right) \frac{d l}{d \mu}-\sum_{i=1}^{n}\left(q_{i} \frac{\partial x_{i}}{\partial \mu}\right)}$.

To determine the sign of expression (3.5), begin with the denominator. Differentiating the first-order condition for labor effort, $l$, expression (3.3), with respect to $\mu$, and rearranging terms, produces

(3.6) $\frac{d l}{d \mu}=\frac{w\left(1-T^{\prime}\right)}{z^{\prime \prime}+\mu w^{2} T^{\prime \prime}}>0$. 
The inequality in expression (3.6) follows because the denominator must be positive according to the second-order condition for the choice of $l$ (the denominator is the negative of the second derivative of the individual's Lagrangian with respect to $l$ ). Differentiating expression (3.2) with respect to $\mu$ yields

(3.7) $\frac{\partial x_{i}}{\partial \mu}=-\frac{\alpha_{i}}{\rho_{i} q_{i} \mu^{2}}\left(\frac{\alpha_{i} \beta_{i}}{\mu q_{i}}\right)^{\frac{1-\rho_{i}}{\rho_{i}}}<0$.

Expressions (3.6) and (3.7) together imply that the denominator of expression (3.5) is positive. Accordingly, the sign of $d \mu / d \phi_{k}$ is the same as the sign of $\partial x_{k} / \partial \phi_{k}$.

This result can be explained as follows. Suppose, for example, that $\partial x_{k} / \partial \phi_{k}>0$. In this case, the direct effect of raising $\phi_{k}$ is to induce the individual to purchase more of $x_{k}$, which through the budget constraint requires some combination of reductions in expenditures on the other $x_{i}$ 's $(i \neq k)$ and an increase in $l$, both of which imply a higher $\mu$, which is apparent from expressions (3.2) and (3.3).

To sign the $d \mu / d \phi_{k}$ 's, therefore, all that remains is to sign the $\partial x_{k} / \partial \phi_{k}$ 's, which is straightforward from expression (3.2).

(3.8) $\frac{\partial x_{i}}{\partial \alpha_{i}}=\frac{\beta_{i} x_{i}+\gamma_{i}}{\rho_{i} \alpha_{i} \beta_{i}}>0$

(3.9) $\frac{\partial x_{i}}{\partial \beta_{i}}=\frac{x_{i}}{\beta_{i}} \frac{1-\rho_{i}}{\rho_{i}}+\frac{\gamma_{i}}{\rho_{i} \beta_{i}^{2}}$.

(3.10) $\frac{\partial x_{i}}{\partial \gamma_{i}}=-\frac{1}{\beta_{i}}<0$.

(3.11) $\frac{\partial x_{i}}{\partial \delta_{i}}=0$

Expression (3.8) implies that $\partial \mu / \partial \alpha_{i}>0$. Because $v_{c}=\mu$, it follows that the overall effect on the social marginal value of consumption, $W^{\prime} v_{c}$, of raising $\alpha_{i}$ is ambiguous: utility rises, so $W^{\prime}$ falls if $W$ is strictly concave; however, marginal utility rises, so $v_{c}$ rises. Those with a higher $\alpha_{i}$ get more out of consuming $x_{i}$, which has these two competing effects. 
Although one might have expected the effect of $\beta_{i}$ to be qualitatively similar, this is not the case. Examination of expression (3.9) reveals that the sign of $\partial \mu / \partial \beta_{i}$ is ambiguous. For convenience, interpretation is confined to the benchmark case in which $\gamma_{i}=0$. (When this is not so, the critical value of $\rho_{i}$ for which the sign of the expression reverses would be adjusted accordingly.) If $\rho_{i}<1$, then $\partial \mu / \partial \beta_{i}>0$, and the results are indeed like those in the prior case. However, if $\rho_{i}>1$, then $\partial \mu / \partial \beta_{i}<0$, and the marginal utility effect combines with the effect on $W^{\prime}$ to reduce the social marginal valuation of consumption. The difference arises because the $\beta_{i}$ coefficient in expression (2.4) directly multiplies $x_{i}$ and thus is subject to the concavity of the subutility function; when that concavity is sufficiently high $\left(\rho_{i}>1\right)$, the diminishing returns effect dominates the efficiency effect in determining how marginal utility changes. Note that, when $\rho_{i}=1$, marginal utility is unchanged.

Combining these two results, we can see that there are two senses in which an individual might be seen to get "more" out of a good $x_{i}$ than do others. In the former case, the contribution to utility of good $x_{i}$ is multiplied by the factor $\alpha_{i}$. In the latter case, there is a sense in which the effective quantity of good $x_{i}$ is multiplied by the factor $\beta_{i}$. As mentioned in subsection 2.2, one might interpret the former as an individual enjoying a good more and the latter as an individual being able to use a good more effectively. These notions are similar but not the same.

Expression (3.10) indicates that $\partial \mu / \partial \gamma_{i}<0$. A higher $\gamma_{i}$ is thus associated with higher utility and lower marginal utility, which unambiguously reduces the marginal social welfare weight $W^{\prime} v_{c}$. As suggested previously, an individual with a higher $\gamma_{i}$ may be thought of as naturally endowed with more of the good before purchasing any in the market. Or, put another way, taking a benchmark value of 0 , a negative $\gamma_{i}$ would indicate a type of disability; the individual needs to purchase some amount of $x_{i}$ to reach the same starting point as others. Clearly, an individual with a lower $\gamma_{i}$ has both lower total utility and higher marginal utility, which unambiguously implies a higher social welfare weight.

Finally, expression (3.11) displays the obvious result that $\partial \mu / \partial \delta_{i}=0 . \quad A$ higher $\delta_{i}$ implies a higher utility level but no difference in marginal utility, and thus a lower social welfare weight $W^{\prime} v_{c}$ if and only if the SWF is strictly concave. Indeed, as is apparent from expression (2.4) and as noted previously, the parameter $\delta_{i}$, despite its subscript, is not commodity-specific. All of the $\delta_{i}$ 's might be aggregated into a single parameter $\delta$ for present purposes.

To summarize, the analysis in this subsection reveals that preference differences that all imply higher utility levels can nevertheless have qualitatively different implications for individuals' marginal utilities of consumption. Moreover, marginal utility is directly relevant to the marginal social welfare weight and thus to determining how preference differences should affect optimal nonlinear income taxation. Indeed, with a utilitarian SWF, it is only the effect on marginal utility that matters. With strictly concave welfare functions, the utility level matters as well, 
and, depending on the type of difference in preference, its strength, and the concavity of utility and of the SWF, individuals who have preferences that generate greater utility for a given level of disposable income may receive higher or lower marginal social welfare weights on their disposable income and thus optimally be subject to lower or higher levels of income taxation. ${ }^{7}$

\section{OPTIMAL COMMODITY TAXATION WITH UNOBSERVABLE TYPES}

The analysis in section 3 takes preferences to be observable, whereas here preference differences are assumed to be entirely unobservable. ${ }^{8}$ As a consequence, it is no longer possible to redistribute across preference types through the income tax. When $\theta$ is not observed, the income tax schedule $T$ in expression (2.3) must be the same for all types. The terms on the right side in this first-order condition accordingly represent weighted averages of sorts. Notably, $W^{\prime} v_{c}$ is the product of the social welfare weight and marginal utility of consumption, averaged for all types at each level of earnings, $w l^{9}{ }^{9}$

This limitation on across-preference-type redistribution through type-specific $T$ schedules means that (even with weak labor separability) differential commodity taxation has a potential role to improve social welfare. Specifically, if individuals who have above-average demands for some commodity $x_{i}$ would ideally - that is, if types were observable - be subject to higher (lower) income taxation, then to some

${ }^{7}$ Some ambiguity arises in interpreting any conclusion about how heterogeneity influences the level of optimal marginal income tax rates because of different possible benchmarks for comparison. Ceteris paribus, a higher welfare weight on a marginal dollar does favor lower income taxation, as discussed in the text. But, as note 6 mentions, heterogeneity has other effects, including on labor effort. Taking, for example, a case in which the marginal utility of consumption is higher, the analysis in the text indicates that labor effort would also be higher. Hence, for a given observed income level $w l$, the higher $l$ implies a lower $w$. Moreover, $w$ is in the denominator of the first-order condition (2.3) for optimal marginal income tax rates, so the lower $w$ favors higher marginal income tax rates, the opposite implication of the higher marginal utility. Accordingly, if labor supply is highly elastic, the effects on optimal tax rates attributable to marginal utility differences could be offset or even reversed.

${ }^{8}$ Realistically, preferences are partially observable, in that preference differences may be signaled by age, physical disabilities, family status, or other factors. To an extent, one can interpret the present analysis as applicable to residual heterogeneity within an identifiable class of individuals, but one would have to take into account limits on the ability to employ different commodity taxes for different classes. Also note that, in addition to limitations due to feasibility and administrative cost, one can also imagine political constraints, for example, on the use of certain factors such as race that might correlate with preferences.

${ }^{9}$ In addition, in the denominator one would have an integral over types of the product $\varepsilon w f$. Regarding $w$, note that different $\theta$ 's may induce individuals of a given $w$ to supply different $l$ 's, so all those at a given income level $w l$ need not be of the same earning ability $w$. 
extent it is optimal to tax (subsidize) that commodity relative to others. These commodity tax adjustments would favorably affect redistribution. In addition, starting from the point of uniform commodity taxation, no first-order loss from consumption distortion would occur. The optimal level of commodity taxes and subsidies would reflect a redistribution-distortion tradeoff, where here the redistribution is "horizontal" (across preference types) and the distortion is of commodity demands (rather than of the labor-leisure choice).

To explore which commodities should be taxed or subsidized, it is necessary first to ascertain the relationship between commodity demands and the preference parameters. Once again, it is helpful to refer to $\phi_{k}$, a generic preference parameter for good $k$. Differentiating the commodity demands (3.2) with respect to $\phi_{k}$ yields

$$
\text { (4.1) } \frac{d x_{k}}{d \phi_{k}}=\frac{\partial x_{k}}{\partial \phi_{k}}+\frac{\partial x_{k}}{\partial \mu} \frac{d \mu}{d \phi_{k}} \text {. }
$$

Note that the first partial derivative term on the right side holds the marginal utility of income constant, but that this effect is taken into account in the second term. Using expression (3.5) for $d \mu / d \phi_{k}$, expression (4.1) can be restated as

$$
\text { (4.2) } \frac{d x_{k}}{d \phi_{k}}=\frac{\partial x_{k}}{\partial \phi_{k}}\left(1+\frac{q_{k} \frac{\partial x_{k}}{\partial \mu}}{w\left(1-T^{\prime}\right) \frac{d l}{d \mu}-\sum_{i=1}^{n}\left(q_{i} \frac{\partial x_{i}}{\partial \mu}\right)}\right)
$$

The denominator of the fractional term in large parentheses on the right side of expression (4.2) is the same as the denominator on the right side of expression (3.5) for $d \mu / d \phi_{k}$, and this was previously shown to be positive. Specifically, the first term of the denominator is positive and each term in the summation is negative. From the latter, it follows that the numerator in the fractional term is negative. Moreover, this numerator is equal to the $k^{\text {th }}$ term in the summation in the denominator. Taken together, these features imply that the value of the term in large parentheses is in the interval $(0,1)$. Therefore, expression (4.2) indicates that the total derivative $d x_{k} / d \phi_{k}$ has the same sign as the partial derivative $\partial x_{k} / \partial \phi_{k}$ but is smaller in magnitude. This result is in accord with intuition: The total effect on demand is given by starting with the effect when $\mu$, the marginal utility of consumption, is taken to be constant and then dampening it by the resulting adjustment in $\mu$. For example, if the partial derivative indicates that demand would rise, this rise in demand is financed partly by 
reducing demands for other goods and partly by increasing labor supply, both of which imply a higher $\mu$, and the higher $\mu$ reduces the magnitude of the increase in demand, but not to zero.

Because each of the partial derivatives $\partial x_{k} / \partial \phi_{k}$ was signed in subsection 3.2, in expressions (3.8) through (3.11), we can now consider how preference heterogeneity bears on optimal differentiation of commodity taxes. Suppose initially that the only heterogeneity involves parameter $\alpha_{i}$ for some good $x_{i}$. From expressions (3.8) and (4.2), it follows that individuals who have a higher $\alpha_{i}$ than do others have a higher demand for $x_{i}$, ceteris paribus. Furthermore, the analysis in subsection 3.2 indicates that the direction of the ideal redistributive adjustment (i.e., the adjustment to $T$ if $\theta$ were observable) depends on the SWF. The reason is that a higher $\alpha_{i}$ implies a higher marginal utility $v_{c}$ but also a higher utility level and thus a lower $W^{\prime}$ if the SWF is strictly concave. ${ }^{10}$ For concreteness, suppose that the SWF is utilitarian, in which case $W^{\prime}$ is constant; then only the marginal utility effect is relevant, so it is unambiguously optimal to redistribute toward high- $\alpha_{i}$ individuals. Since they have higher demands for $x_{i}$, some degree of subsidy would be optimal. ${ }^{11}$ Note that the use of the term subsidy here refers to a relative subsidy (and likewise for later uses of the term tax); instead of subsidizing good $x_{i}$, one could instead (equivalently) tax all other goods and adjust $T$ accordingly.

As one generalizes to cases involving preference heterogeneity relating to many commodities, the problem becomes more complex. For example, suppose that heterogeneity exists regarding all of the $\alpha_{i}$ 's. The preceding analysis suggests that one would like to relatively subsidize all goods, which is impossible-i.e., the effects of the different subsidies would be offsetting. Taking a more concrete example, suppose that some types of individuals have uniformly higher $\alpha_{i}$ 's than do others. Under the utilitarian SWF, it would be ideal to redistribute income to them; however, this cannot be done through differential commodity taxation because, in this case, relative demands would be unaffected.

Combining the preceding points, it appears that it would be optimal to subsidize goods relatively preferred by types whose overall or average levels of the $\alpha_{i}$ 's are higher. To illustrate, assume that individuals with generally higher $\alpha_{i}$ 's have an $\alpha_{j}$ that is relatively low for them. The prescription would be to relatively subsidize all goods except good $x_{j}$-i.e., to relatively tax good $x_{j}$, even if these

\footnotetext{
${ }^{10}$ Here and throughout this section, one should keep in mind the qualification in note 7 regarding the direction and magnitude of optimal adjustments to income taxation when those adjustments derive from differences in marginal utilities of consumption.

${ }^{11}$ Observe that any effects of such a subsidy across income levels (for example, with a normal good, higher-ability individuals who earn higher incomes spend more on the good and thus benefit more from the subsidy, even if they have the same $\alpha_{i}$ as others) can be offset through the $T$ schedule.
} 
individuals' $\alpha_{j}$ 's are above the population average (although lower than the average of their own, other $\alpha_{i}$ 's).

Alternatively, suppose that each of the $\alpha_{i}$ 's is independently distributed. In that case, it would seem advantageous under a utilitarian SWF to impose relative subsidies on the goods with the greatest variance in the distribution of the $\alpha_{i}$ 's, whereas relative taxes may be optimal if the SWF is sufficiently concave. The intuition is that, on average, subsidies would provide a larger benefit to high- $\alpha_{i}$ individuals, and to a greater degree the higher are their $\alpha_{i}$ 's. This point is most easily seen in the limiting case in which the variance for one of the $\alpha_{i}$ 's is large and that for all of the others approaches zero, which presents the original case with heterogeneity for only one of the $\alpha_{i}$ 's. ${ }^{12}$

Similar analysis applies to the other parameters. For example, higher $\gamma_{i}$ 's imply both lower marginal utility (see expression 3.10) and a higher utility level, so we would ideally like to redistribute away from individuals with atypically high $\gamma_{i}$ 's. Furthermore, high- $\gamma_{i}$ individuals have lower demands for corresponding goods $x_{i}$, so it would be ideal to subsidize goods for which some individuals have unusually high $\gamma_{i}$ 's. (With the $\alpha_{i}$ 's, commodity subsidies favor individuals with high values of the parameter; with the $\gamma_{i}$ 's, subsidies favor individuals with low values.) But, as with the $\alpha_{i}$ 's, one cannot relatively subsidize all goods, so one must consider relative differences in parameter values.

For the parameter $\delta$, higher values indicate no difference in marginal utility (see expression 3.11) but higher total utility and thus a lower $W^{\prime}$ if the SWF is strictly concave. However, because the value of $\delta$ has no influence on commodity demands, commodity taxes cannot be employed directly to accomplish any desired redistribution.

For the parameter $\beta$, the situation is more complicated. From expression (3.9), the sign of the marginal utility effect — and, accordingly, from expression (4.2), the sign of the demand effect-depends on the magnitude of the pertinent $\rho_{i}$ (abstracting from the further adjustment required when the corresponding $\gamma_{i}$ does not equal zero). For example, if heterogeneity concerns a particular $\beta_{i}$, and we consider the case in which $\rho_{i}<1$, then high- $\beta_{i}$ individuals have higher marginal utilities, ceteris paribus, and under a utilitarian SWF it would be optimal to redistribute toward them. In this case, such individuals also have higher demands, so a commodity subsidy would be optimal. If instead $\rho_{i}>1$, then high- $\beta_{i}$ individuals have lower marginal utilities, so it would be optimal to redistribute away from them. In this alternative case, however, such individuals have lower demands, so again a

\footnotetext{
${ }^{12}$ The magnitude of the corresponding $\rho_{i}$ 's would also matter, for $\rho_{i}$ affects the magnitude of the utility level and marginal utility effects and also the magnitude of demand effects, including the demand elasticity, which is related to the distortionary cost being traded off against the redistributive benefit.
} 
subsidy (which would favor low- $\beta_{i}$, high-demand individuals) would be optimal. In both instances, note that the ability to use commodity taxation to redistribute is limited the closer that $\rho_{i}$ is to 1 ; when $\rho_{i}=1$, heterogeneity regarding $\beta_{i}$ has no effect on demand for that commodity, so across-preference-type redistribution through commodity taxes is infeasible (and also would not be optimal with a utilitarian SWF, although it would be if the SWF was strictly concave). ${ }^{13}$

The optimal use of differential commodity taxation actually depends on the combination of all of the parameters. As a group, they determine whether it would be optimal to redistribute toward or away from an individual of a given overall preference type $\theta$. Furthermore, as a group they determine the direction of any differences in demand. Even for a specified SWF, such as a utilitarian one, the ideal direction of redistribution sometimes is in the same direction and sometimes is in the opposite direction of the corresponding demand effect. Accordingly, broad generalizations about preference heterogeneity and the signs of optimal deviations from uniform commodity taxation cannot be offered.

It may be possible, however, to identify some particular effects. It seems plausible that some individuals toward whom it would be optimal to redistribute do systematically demand more of certain commodities. This might include those with physical limitations (the goods might be types of medical care or disability accommodations such as wheelchairs) or mental infirmities (the goods might be certain drugs or psychiatric care). To some degree, the analysis of section 3 may be applicable because some of these differences in preferences correspond to observable differences, in which case heterogeneity-motivated redistribution should (in the benchmark case with separable labor) be accomplished entirely through the income tax. But some physical and mental infirmities may be more difficult to observe, so differential commodity taxation may play a useful role. In this regard, it should be noted that optimal differential taxation may be appropriate for more than the obvious goods, such as those already noted. For example, individuals with more hidden physical disabilities might engage less in physically strenuous activities (skiing) and more in gentler activities; those with certain psychological difficulties likewise may have atypically high demand for some commodities and low demand for others. What matters, it should be recalled, is various individuals' relative demands. Thus, some impaired individuals might have an unusually low $\alpha_{i}$ for some commodity, but this parameter value may still be relatively high for them, and it in turn may imply higher demand, which would favor a subsidy.

\footnotetext{
${ }^{13}$ The existence of little or no demand effect due to differences in $\beta_{i}$ 's does not, however, imply that no distortion in commodity demands results from differential taxation.
} 
The B.E. Journal of Economic Analysis \& Policy, Vol. 8 [2008], Iss. 1 (Advances), Art. 40

\section{Public Goods And Externalities}

\subsection{Public Goods}

To introduce public goods, modify the initial utility function to be $u(x, g, l, \theta)$, where $g$ is a vector of $m-n$ public goods (and $m$ is now the total number of private and public goods). Likewise, the specific utility function (2.4) can be amended as follows:

$$
\text { (5.1) } \begin{aligned}
u(x, l, \alpha, \beta, \gamma, \delta, \rho) & =\sum_{i=1}^{n}\left(\alpha_{i} \frac{\left(\beta_{i} x_{i}+\gamma_{i}\right)^{1-\rho_{i}}}{1-\rho_{i}}+\delta_{i}\right) \\
& +\sum_{i=n+1}^{m}\left(\alpha_{i} \frac{\left(\beta_{i} g_{i}+\gamma_{i}\right)^{1-\rho_{i}}}{1-\rho_{i}}+\delta_{i}\right)-z(l) .
\end{aligned}
$$

As before, for the case in which $\rho_{i}=1$, the fractional expressions are replaced by $\ln \left(\beta_{i} x_{i}+\gamma_{i}\right)$ and $\ln \left(\beta_{i} g_{i}+\gamma_{i}\right)$ respectively.

Consider first the case in which $\theta$ is observable. With weak labor separability, which expression (5.1) exhibits, the proofs in Kaplow (1996, 2006c) on the optimality of the Samuelson rule for public goods provision-without adjustments for distribution or labor supply distortion - go through. The reasoning is analogous to that in subsection 3.1, as the proofs in Kaplow $(1996,2006 \mathrm{c})$ are in relevant respects analogous to that in Kaplow (2006a) for uniform commodity taxation. Thus, in summing or integrating individuals' marginal benefits (measured in dollars) from more of a public good, each individual's possibly idiosyncratic valuation would be employed; this total, whatever it may be, is then compared with the marginal cost of increased provision, just as in the case with homogeneous preferences. $^{14}$

Accordingly, the effect of observable preference heterogeneity regarding public goods on optimal policy is entirely through the income tax schedules $T(w l, \theta)$, which are customized for each preference type. These effects, however, are qualitatively different from those deriving from heterogeneous preferences for commodities. The reason is that, although differences in the $\phi_{k}$ 's, for $k>n$ (i.e., for the public goods) affect utility levels analogously (utility is increasing in each of $\alpha$, $\beta, \gamma$, and $\delta$ ), differences in these $\phi_{k}$ 's do not affect individuals' marginal utilities of

\footnotetext{
${ }^{14}$ This total, to be sure, may be influenced by heterogeneity itself. As it turns out, greater heterogeneity (with a constant mean) can raise or lower the sum of marginal benefits, depending on the preference parameter that varies (and the level of the corresponding $\rho_{i}$ ).
} 
consumption of private goods. Accordingly, for a utilitarian SWF, the optimal income tax schedule would not be adjusted, and for a strictly concave SWF, higher values of these parameters imply higher utility and thus a lower $W^{\prime}$, so optimal levels of income taxation would be higher.

This irrelevance result concerning marginal utilities is due to the separability between public and private goods embodied in the utility function (5.1). More generally, marginal utility effects in either direction are possible. For example, better roads may make automobiles more valuable, and one could imagine this arising in a manner that increased individuals' marginal utilities of consumption by a larger amount for individuals who had a stronger preference for driving. Suppose further that this greater preference operated through the corresponding $\alpha_{i}$ (perhaps the $\alpha_{i}$ for driving would be multiplied by $\alpha_{j} g_{j}$ for roads). Then high- $\alpha_{j}$ individuals would have a higher "effective" $\alpha_{i}$, which, ceteris paribus, implies a higher marginal utility of consumption, so under a utilitarian SWF their optimal level of income taxation would be lower on this account.

Now consider the case in which $\theta$ is unobservable. The analysis of the optimal income tax would be analogous to that described in section 4 on unobservable heterogeneity in preferences for commodities. It might appear that there is no implication corresponding to the nonuniform commodity tax results since all individuals necessarily receive the same amount of each public good-i.e., differences in consumption patterns do not exist and thus may seem to render differential treatment infeasible. But this supposition is incorrect. By providing more or less of the public good than the amount indicated by the Samuelson rule, different preference types can be favored and disfavored: Raising (lowering) the level of the public good provides disproportionate benefits to those with a higher (lower) marginal utility for that good (assuming distribution-neutral finance of the sort described in subsection 3.1).

The remaining question is which goods should thus be over- or underprovided relative to the level that satisfies the Samuelson rule. Once again, with preferences separable between public and private goods and a utilitarian SWF, we have no basis for deviation since heterogeneity in preferences for public goods does not influence individuals' marginal utilities of consumption. If the SWF is strictly concave or if cross-effects exist, then the previous comments for the case of observable preferences would become relevant. ${ }^{15}$ For example, with a strictly concave $W$, if individuals with overall detrimental preference parameters (i.e., those whose preference parameters generate less utility from public and private goods at a given income level) tend to derive atypically high marginal utility from public

\footnotetext{
${ }^{15}$ When there are public goods, optimal commodity taxation may also be influenced in related ways.
} 
good $j$, then more of that public good should be provided. To be concrete, suppose that individuals who are unusually vulnerable to being mugged also tend to be worse off in other respects (which cannot readily be observed). In this case, greater police protection would have a favorable distributive effect. By contrast, if national parks are most enjoyed by more robust individuals, who otherwise tend to be better off on average, then lower provision would be distributively beneficial.

\subsection{EXTERNALITIES}

To examine externalities instead of public goods, one can modify the initial utility function to be $u(x, e, l, \theta)$, where $e$ is a vector of $m-n$ externalities. For concreteness, one might take $m=2 n$ and suppose that each externality is measured by the total consumption of the corresponding commodity. Analogous to expression (5.1), the specific utility function (2.4) becomes:

$$
\text { (5.2) } \begin{aligned}
u(x, l, \alpha, \beta, \gamma, \delta, \rho) & =\sum_{i=1}^{n}\left(\alpha_{i} \frac{\left(\beta_{i} x_{i}+\gamma_{i}\right)^{1-\rho_{i}}}{1-\rho_{i}}+\delta_{i}\right) \\
& +\sum_{i=n+1}^{m}\left(\alpha_{i} \frac{\left(\beta_{i} e_{i}+\gamma_{i}\right)^{1-\rho_{i}}}{1-\rho_{i}}+\delta_{i}\right)-z(l) .
\end{aligned}
$$

(The modification for the case in which $\rho_{i}=1$ is analogous as well.) For a negative externality $e_{i}$, the corresponding $\alpha_{i}$ would be negative. Observe that, in this formulation, externalities have a public good character: Each individual is exposed to the same levels of the $e_{i}$ 's, although different preference types are affected differently by any particular $e_{i}$. Thus, the sum (integral) of marginal external benefits or harms for purposes of applying the Pigouvian rule of setting commodity taxes and subsidies equal to marginal harm and benefit, respectively, is directly analogous to the sum of marginal benefits in the public goods case.

At this point it should be unsurprising that the analysis closely parallels that for public goods. When $\theta$ is observable and weak labor separability is assumed, as in expression (5.2), we can employ the proof method in Kaplow (2006b) to show that there should be no adjustment to the Pigouvian rule on account of distribution or labor supply distortion. (Extensions for partial reforms that are analogous to those considered for commodity taxation continue to hold here as well.) Once again, heterogeneous preferences would only be relevant in setting the income tax schedules $T(w l, \theta)$, and the pertinent adjustments would follow the same sort of reasoning applicable for public goods. For example, in expression (5.2) in which private goods and externalities have separable effects, externalities - and thus 
differences in preference parameters regarding externalities - affect utility levels but not the marginal utility of consumption, so heterogeneous preferences regarding externalities would only be relevant to optimal income taxation to the extent that the SWF is strictly concave. Relaxing this separability assumption would allow for interactions.

When $\theta$ is not observable, it may be optimal to depart from the pure Pigouvian rule. Although individuals all experience the same levels of the externalities, different types of individuals can be favored or disfavored by regulating externalities more or less than indicated by the Pigouvian rule. ${ }^{16}$ For example, if some pollutant imposes greater marginal harm on more infirm individuals who also tend to be worse off in other (unobservable) respects, greater control of that pollutant would tend to be optimal under a strictly concave SWF. Likewise, just as it may have been optimal to reduce expenditures on national parks that disproportionately benefit more robust individuals who are otherwise better off on average, so it may be optimal to reduce (relative to the Pigouvian optimum) the control of pollution that primarily interferes with the enjoyment of wilderness areas.

\section{WeLFARE ECONOMIC CONSIDERATIONS}

Analysis of optimal taxation, public goods provision, and the control of externalities, like most policy analysis conducted by economists, is grounded in the welfare economic tradition, which is controversial. Taking the SWF to be linear - that is, utilitarian-further adds to the dispute. ${ }^{17}$ Certain issues that have been central in these normative debates are brought to the fore when heterogeneous preferences are introduced.

Problems of interpersonal comparisons of utility are often circumvented by treating all individuals as if they are identical. But when heterogeneity involves aspects of utility that give rise to different demands, this approach is no longer available, even if it could otherwise be defended. Furthermore, the formal meaning of ignoring differences is ambiguous and incomplete because the outcome depends on what preferences are deemed normal; moreover, when taste differences are associated with, say, disabilities, many would find the case for recognizing rather than ignoring differences to be particularly compelling. Of course, many taste differences can neither be observed nor well estimated, making it difficult for policies to reflect them. But when differences are observed or the nature of

\footnotetext{
${ }^{16}$ Since the regulation of externalities is taken here to be implemented through commodity tax adjustments, differences in preferences for commodities are also relevant to across-preference-type redistribution, but that is already captured by the analysis in section 4 .

${ }^{17}$ For differing perspectives, see Hare (1981), Sen and Williams (1982), and Kaplow and Shavell (2002).
} 
underlying heterogeneity can be determined to some extent, optimality does in principle require taking such differences into account. ${ }^{18}$

If preference differences are granted, the necessary interpersonal comparisons raise issues of cardinalization, which has been noted, for example, by Boadway et al. (2002) and Sandmo (1993). For example, if individuals are observed to have a certain disability, say blindness, it is necessary to determine how much this affects their utility level (if the SWF is strictly concave) and their marginal utility of consumption. ${ }^{19}$ In order for a social response to be based on how the disability actually affects individuals (rather than on some criteria that is independent of wellbeing), such questions must somehow be answered, at least approximately.

Finally, unlike in most analyses (other than of the optimal income tax itself), the degree of concavity of the SWF must be specified. Indeed, to set commodity taxes, which optimally involve differentials in the case in which preference differences are unobservable, even the signs of the optimal deviations from uniformity depend on the curvature of the SWF. Although notable economists, like Harsanyi (1953, 1955), and others, such as Rawls (1971), have famously staked out positions on this question, debate has hardly subsided.

Some have reacted to prior drafts and presentations of this paper by suggesting that explicit analysis of optimal policy with heterogeneity bolsters the case against utilitarianism and perhaps welfare economics more broadly. I disagree. Having presented my views on these and related questions at length in Kaplow and Shavell (2002) and Kaplow (2008, chapters 13-15), I offer no further elaboration here. What does seem apparent, however, is that analysis of heterogeneity - whether in the setting of physical and mental disabilities or otherwise-does prompt reflection on these fundamental normative questions.

\footnotetext{
${ }^{18}$ An alternative approach is arguably implicit in Rawls (1971) and Sen (1985), who would determine allocations, respectively, based on conceptions of primary goods or functionings and capabilities, rather than based on individuals' utilities, even if they could reliably be determined. But as Kaplow (2007) shows, these approaches conflict with the Pareto principle (as do deviations from welfarism more generally, on which see Kaplow and Shavell, 2001).

${ }^{19}$ A utilitarian SWF requires a degree of interpersonal comparison that is referred to in the social choice literature as cardinal unit comparability. Note that von Neumann-Morgenstern utility functions are cardinal, due to rationality axioms; unit comparability further requires the ability to relate the cardinal units of one person's utility to those of another's. A strictly concave SWF also requires level comparability, which together with cardinal unit comparability amounts to cardinal full comparability. For further discussion, see Sen (1977). A maximin SWF only requires level comparability because only the utility of the least-well-off individual matters; however, $\mathrm{Ng}$ (1984a) has shown that, when combined with the axioms of individual rationality, this seemingly lesser assumption implies unit and thus full comparability in any event.
} 
Kaplow: Optimal Policy with Heterogeneous Preferences

\section{CONCLUSION}

Heterogeneous preferences undoubtedly exist and in some instances may be important. Accordingly, it is useful to revisit optimal policy rules that have been derived in models in which preferences are taken to be homogeneous. The results depend greatly on whether preference differences are observable and on the nature of those differences.

With observability, a number of first-best policy prescriptions in benchmark cases (notably, with weak labor separability) continue to hold. This conclusion is true of the Atkinson-Stiglitz (1976) rule favoring uniform commodity taxation as well as generalizations that do not require the income tax to be optimal and that encompass partial reforms, such as proportional moves toward uniformity. Likewise, results regarding the Pareto optimality of moving public goods provision in the direction indicated by the Samuelson rule and Pigouvian taxes and subsidies toward full internalization of externalities - without regard to concerns for distribution and labor supply distortion - also extend to the present setting.

The characterization of optimal nonlinear income taxation, however, changes in important ways. Groups with preference parameters indicating higher utility levels are, ceteris paribus, optimally subject to higher levels of income taxation - some combination of higher marginal tax rates and a lower grant - to the extent that the SWF is strictly concave. But different sorts of preference parameters have different effects on individuals' marginal utilities of consumption and thus parameters producing higher utility levels may favor higher or lower income taxation.

When differences in preferences are unobservable, a single income tax schedule must be applied to everyone, and optimal marginal income tax rates are determined similarly to the manner applicable with homogeneous preferences. (Roughly, weighted averages substitute for specific values, but the basic formula is the same.) In this case, it is the more specific policy rules that may differ qualitatively from what arises with homogeneous preferences. Differential commodity taxation, public goods provision that deviates from the levels implied by the Samuelson rule, and corrective taxes that over- or under-internalize externalities are optimal to some degree in cases in which such deviations can indirectly accomplish some of the across-preference-type redistribution that would have been implemented through differentiated income tax schedules if preference differences were observable. Examples were offered that involve some possible manifestations of physical and mental disabilities.

Overall, departures from results in models with homogeneous preferences depend on a variety of factors. Different ways in which preferences might vary have qualitatively different effects, even in opposite directions. Furthermore, preference differences interact with each other and with the various policy instruments in 
complex and subtle ways. The problem of heterogeneous preferences is indeed heterogeneous.

Accordingly, conjectures and results in existing literature on heterogeneity need to be interpreted as special cases in ways that have not previously been recognized; indeed, a change in specifications of preference differences can reverse results. Nevertheless, some plausible conjectures can be offered when it is possible to ascertain the character of preference differences, even if they cannot be observed for each individual. These findings may have direct policy relevance, and they indicate the value of empirical research on preference heterogeneity.

\section{REFERENCES}

Armstrong, Mark, and Jean-Charles Rochet. 1999. "Multi-dimensional Screening: A User's Guide.” European Economic Review 43: 959-979.

Atkinson, Anthony B., and Joseph E. Stiglitz. 1976. "The Design of Tax Structure:

Direct versus Indirect Taxation." Journal of Public Economics 6: 55-75.

$\longrightarrow$ and $\longrightarrow$ 1980. Lectures on Public Economics. New York: McGrawHill.

Blackorby, Charles, and David Donaldson. 1988. "Cash versus Kind, SelfSelection, and Efficient Transfers." American Economic Review 78: 691-700.

Boadway, Robin, and Michael Keen. 1993. "Public Goods, Self-Selection and Optimal Income Taxation." International Economic Review 34: 463-478

Boadway, Robin, Maurice Marchand, Pierre Pestieau, and Maria del Mar Racionero. 2002. "Optimal Redistribution with Heterogeneous Preferences for Leisure." Journal of Public Economic Theory 4: 475-498.

Cremer, Helmuth, Pierre Pestieau, and Jean-Charles Rochet. 2001. "Direct versus Indirect Taxation: The Design of the Tax Structure Revisited." International Economic Review 42: 781-800.

Diamond, Peter. 1975. "A Many-Person Ramsey Tax Rule.” Journal of Public Economics 4: 335-342.

Ebert, Udo. 1988. "Optimal Income Taxation: On the Case of Two-Dimensional Populations." University of Bonn, Graduate School of Economics Discussion Paper No. A-169.

Fleurbaey, Marc. 2006. "Is Commodity Taxation Unfair?” Journal of Public Economics 90: 1765-1787.

Hare, Richard M. 1981. Moral Thinking: Its Levels, Method, and Point. New York: Oxford University Press.

Harsanyi, John C. 1953. "Cardinal Utility in Welfare Economics and in the Theory of Risk-Taking." Journal of Political Economy 61: 434-435.

—. 1955. "Cardinal Welfare, Individualistic Ethics, and Interpersonal Comparisons of Utility." Journal of Political Economy 63: 309-321. 
Kaplow: Optimal Policy with Heterogeneous Preferences

Hellwig, Martin F. 2004. “Optimal Income Taxation, Public-Goods Provision and Public-Sector Pricing: A Contribution to the Foundations of Public Economics." Max Planck Institute for Research on Collective Goods Working Paper 2004/14. Bonn, Germany.

Hylland, Aanund, and Richard Zeckhauser. 1979. "Distributional Objectives Should Affect Taxes But Not Program Choice or Design." Scandinavian Journal of Economics 81: 264-284.

Kaplow, Louis. 1996. "The Optimal Supply of Public Goods and the Distortionary Cost of Taxation." National Tax Journal 49: 513-533.

_ 2006a. "On the Undesirability of Commodity Taxation Even When Income Taxation Is Not Optimal." Journal of Public Economics 90: 1235-1250.

-. 2006b. "Optimal Control of Externalities in the Presence of Income Taxation." NBER Working Paper 12339. Cambridge, MA.

—. 2006c. "Public Goods and the Distribution of Income." European Economic Review 50: 1627-1660.

—. 2007. "Primary Goods, Capabilities, ... or Well-Being?" Philosophical Review 116: 603-632.

- 2008. The Theory of Taxation and Public Economics. Princeton: Princeton University Press.

Kaplow, Louis, and Steven Shavell. 2001. "Any Non-welfarist Method of Policy Assessment Violates the Pareto Principle." Journal of Political Economy 109: 281-286.

— and 2002. Fairness versus Welfare. Cambridge, Mass.: Harvard University Press.

Konishi, Hideo. 1995. "A Pareto-Improving Commodity Tax Reform under a Smooth Nonlinear Income Tax." Journal of Public Economics 56: 413-446.

Laroque, Guy. 2005. "Indirect Taxation Is Superfluous under Separability and Taste Homogeneity: A Simple Proof." Economics Letters 87: 141-144.

Marchand, Maurice, Pierre Pestieau, and Maria Racionero. 2003. "Optimal Redistribution When Different Workers Are Indistinguishable." Canadian Journal of Economics 36: 911-922.

Mirrlees, James A. 1976. "Optimal Tax Theory: A Synthesis." Journal of Public Economics 6: 327-358.

$\mathrm{Ng}$, Yew-Kwang. 1984a. "Interpersonal Level Comparability Implies Comparability of Utility Differences." Theory and Decision 17: 141-147.

_. 1984b. "Quasi-Pareto Social Improvements." American Economic Review 74: 1033-1050.

Rawls, John. 1971. A Theory of Justice. Cambridge, Mass.: Harvard University Press. 
The B.E. Journal of Economic Analysis \& Policy, Vol. 8 [2008], Iss. 1 (Advances), Art. 40

Saez, Emmanuel. 2002. "The Desirability of Commodity Taxation under Non-linear Income Taxation and Heterogeneous Tastes." Journal of Public Economics 83: 217-230.

Sandmo, Agnar. 1993. "Optimal Redistribution When Tastes Differ." Finanz Archiv 50: 149-163.

Sen, Amartya. 1977. "On Weights and Measures: Informational Constraints in Social Welfare Analysis.” Econometrica 45: 1539-1572.

. 1985. Commodities and Capabilities. Amsterdam: North-Holland.

Sen, Amartya, and Bernard Williams, eds. 1982. Utilitarianism and Beyond. Cambridge: Cambridge University Press.

Tarkiainen, Ritva, and Matti Tuomala. 1999. "Optimal Nonlinear Income Taxation with a Two-Dimensional Population: A Computational Approach." Computational Economics 13: 1-16. 